\title{
Prevalência de subtipos do HIV-1 no Distrito Federal
}

\author{
Daniela Marreco Cerqueira ${ }^{l}$ \\ Eduardo Dias Ramalho ${ }^{I}$ \\ Claudiner Pereira Oliveira ${ }^{1}$ \\ Ruiter Roberto Silva ${ }^{2}$ \\ Miriam Franchini ${ }^{2}$ \\ Cláudia Renata Fernandes Martins ${ }^{l}$
}

RESUMO - A análise genética de isolados do HIV-1 revelou a existência de, pelo menos, dez subtipos distintos no grupo M (A, B, C, D, F1, F2, G, H, I, J e K). No Brasil, já foram identificados, na população infectada, os subtipos B, C, D e F. Entretanto, a maioria das amostras analisadas até o momento são provenientes das regiões Sul e Sudeste, sendo imprescindível analisar amostras provenientes de outras regiões do país. O subtipo B predomina no Brasil, mas não há dados de caracterização molecular do HIV-1, no Distrito Federal. Nosso objetivo consistiu na determinação dos subtipos de HIV-1 que ocorrem em maior frequiência no DF. A região do genoma viral analisada correspondeu ao gene completo da protease. A caracterização do subtipo do HIV-1, presente nas amostras, foi realizada por PCR e digestão com a enzima de restrição Alu I. Todas as amostras analisadas foram caracterizadas como pertencentes ao subtipo B, o que está de acordo com dados da literatura para o Brasil. O estudo da variabilidade genética do HIV-1 pode fornecer informações importantes para intervenções clínicas que visem alterar ou mesmo interromper a progressão da doença.

Palavras-chave: retroviridae; vírus da imunodeficiência humana; HIV-1; subtipo B

\section{HIV -1 subtypes prevalence in Distrito Federal}

ABSTRACT - Genetic analysis of HIV-1 isolates has revealed at least ten distinct subtypes in group M (A, B, C, D, F1, F2, G, H, I, J and K). In Brazil, subtypes B, $\mathrm{C}, \mathrm{D}$ and $\mathrm{F}$ have already been identified in the infected population. However, the majority of the samples analyzed until now were originally from the South and Southeast regions of the Country. The subtype B predominates in Brazil, but no data on molecular characterization of HIV-1 in Distrito Federal was available until

\footnotetext{
${ }^{1}$ Instituto de Biologia, Universidade de Brasília, Brasília-DFCEP: 70.919-900.

${ }^{2}$ Instituto de Saúde do Distrito Federal, Brasília-DF.
} 
now. Our purpose was to determine the HIV-1 subtypes that occur in higher frequency in DF. The region of the genome that was amplified corresponded to the total protease gene. The identification of the subtype was performed by PCR, followed by digestion with the restriction enzyme $A l u$ I. All analyzed samples were defined as belonging to the subtype $B$ and these results are in agreement with data from other areas of Brazil. Studies on genetic variability of HIV-1 can generate important information for clinical interventions focusing on alteration or interruption of disease progress.

Key words: retroviridae; human immunodeficiency virus; HIV-1; subtype B

O Brasil possui aproximadamente 597 mil portadores do vírus da imunodeficiência humana do tipo 1(HIV-1), incluindo as pessoas que já desenvolveram AIDS. Uma pessoa infectada pelo HIV-1 demora, em média, de oito a dez anos para começar a desenvolver os sintomas da AIDS. Só então é feita a notificação da doença como um caso de AIDS. O número de casos de AIDS no Brasil é de 215.810 (no período de 1980 a junho de 2001). Cerca de 50\% das pessoas com AIDS já foram a óbito. No Distrito Federal, já foram registrados 2.918 de casos de AIDS entre 1980 e 2001 (Brasil, 2002).

O HIV-1 pertence à família Retroviridae, gênero Lentivirus. Os retrovírus são vírus de RNA que se replicam por meio de intermediários de DNA, utilizando nesse processo a enzima viral denominada transcriptase reversa (van Regenmortel et al., 2000). O genoma do HIV-1 possui nove genes. Três desses genes estão envolvidos na síntese de proteínas estruturais. São eles: gag, que codifica as proteínas da matriz, do capsídeo e do nucleocapsídeo; pol, que codifica as enzimas protease, transcriptase reversa e integrase; e env, que codifica as duas glicoproteínas do envelope. Os produtos protéicos dos outros seis genes - vif, vpr, vpu, tat, rev e $n e f$ - estão envolvidos na regulação da expressão do genoma do vírus (Larder et al., 2001).

O HIV-1 pode ser classificado em três grandes grupos: $\mathrm{M}$ (Major), $\mathrm{O}$ (Outlier) e N (non-M/non-O) (Costa et al., 2000). A análise genética de isolados do HIV-1 revelou a existência, dentro do grupo $\mathrm{M}$, de dez subtipos distintos: $\mathrm{A}, \mathrm{B}, \mathrm{C}, \mathrm{D}$, F1, F2, G, H, I, J e K, além de quatro formas recombinantes denominadas CRFs (Circulating Recombinant Forms): AE, AG, AGI e AB. Os subtipos E e I originais nunca foram encontrados, apenas as formas recombinantes. Na Europa Ocidental e nos Estados Unidos, os vírus do subtipo B são predominantes, mas vírus de subtipos não-B e recombinantes têm sido identificados com uma freqüência cada vez maior em diversas localidades (Alvarez et al., 2001; Carr et al., 2000; Robertson et al., 2000). 
Os subtipos do HIV-1 estão distribuídos de maneira distinta em diferentes partes do mundo. Provavelmente, devido ao tipo de vírus fundador que iniciou a epidemia em cada uma dessas regiões. O número de isolados do HIV-1 já caracterizados no Brasil é limitado, especialmente quando se considera a grande área geográfica e alta prevalência do vírus (Sabino et al., 1996). Seguindo a tendência já observada em muitos países em desenvolvimento, é possível verificar a ocorrência de mais de um subtipo do HIV-1 no Brasil. Em geral, o subtipo B tem predominado, sendo relatado em $90 \%$ das amostras já caracterizadas. O subtipo F ocorre em 5 a $8 \%$ dos casos e os subtipos C e D representam menos que $2 \%$ do total (Rossini et al., 2001).

Apesar de já terem sido realizados diversos estudos de caracterização de subtipos do HIV-1 em amostras da população brasileira, não há dados relativos aos subtipos do vírus que ocorrem no Distrito Federal (Diaz et al., 1997). Diversos trabalhos corroboram a idéia de que, mesmo em localidades muito próximas, é possível detectar uma variabilidade significativa quanto aos subtipos de HIV1 circulantes. Além disso, há evidências crescentes de possíveis correlações entre diferentes subtipos de HIV-1 e o risco de aparecimento de genótipos resistentes aos anti-retrovirais (Kanki et al., 1999).

Esse trabalho teve como objetivo determinar o subtipo de HIV-1 que ocorre com maior freqüência, no Distrito Federal, em indivíduos submetidos à terapia anti-retroviral. Trata-se de um estudo anônimo, onde nenhuma das amostras foi correlacionada com dados dos pacientes. A região do genoma viral analisada nessa pesquisa corresponde ao gene da protease.

\section{Material e Métodos}

\section{- Obtenção do RNA}

Foram analisadas vinte e duas (22) amostras contendo RNA viral, obtidas de indivíduos que realizaram testes de carga viral no Instituto de Saúde do Distrito Federal, nos anos de 1998 e 1999. A extração do RNA viral foi feita, utilizando-se o kit NASBA (Organon - Teknika). As amostras não foram identificadas com dados dos pacientes para preservar o anonimato previsto no estudo.

\section{- Síntese do cDNA}

Uma alíquota de $5 \mathrm{ml}$ de cada amostra de RNA foi usada como molde para a síntese da fita de cDNA, por transcrição reversa, com utilização de primers randômicos. 
- Amplificação das amostras

A amplificação do gene da protease foi realizada por nested $\mathrm{PCR}$, com primers já descritos na literatura (Ministério da Saúde, 2000). DP10 e DP11 foram usados como primers externos e DP16 e DP17, como primers internos. Como controle negativo foi utilizada água destilada. As amostras foram processadas em um termociclador, PTC 100 da MJ Research, com o seguinte programa: $1^{\circ}$ Ciclo de $94{ }^{\circ} \mathrm{C}$ por $1 \mathrm{~min}$., $2^{\circ} \mathrm{Ciclo} \mathrm{de} 94{ }^{\circ} \mathrm{C}$ por $30 \mathrm{seg}$.; $57^{\circ} \mathrm{C}$ por 30 seg. e $72{ }^{\circ} \mathrm{C}$ por 30 seg.; 39 ciclos de $94{ }^{\circ} \mathrm{C}$ por 30 seg., $57^{\circ} \mathrm{C}$ por 30 seg. e $72{ }^{\circ} \mathrm{C}$ por 30 seg.; e um último Ciclo de $72{ }^{\circ} \mathrm{C}$ por $5 \mathrm{~min}$.

- Análise do produto de PCR

Para a análise do produto da amplificação, as amostras foram submetidas à eletroforese em gel de agarose $1 \%$ e coloração com $10 \mathrm{mg} / \mathrm{ml}$ de brometo de etídio (Sambrook et al., 1989). Foram consideradas positivas para HIV-1 as amostras que apresentaram uma banda de aproximadamente $297 \mathrm{pb}$, quando comparada com um marcador (ladder), incluído em cada gel.

- Definição do subtipo

Uma alíquota do produto do PCR de cada amostra foi submetida à digestão pela enzima de restrição Alu I. A análise da digestão foi feita em gel de poliacrilamida $15 \%$ corado com brometo de etídio. Esse procedimento, de acordo com dados da literatura, permite a diferenciação de subtipos B, C, D e F que são os que ocorrem no Brasil (Pienniazek et al., 1995).

\section{Resultados}

Todas as 22 amostras foram amplificadas para o gene da protease, obtendo-se um fragmento de, aproximadamente, $300 \mathrm{pb}$, correspondendo ao tamanho esperado (figura 1).

A digestão com a enzima Alu I nos permitiu definir o subtipo de HIV-1 presente nas amostras analisadas. Com base no perfil de digestão observado, foi possível verificar que todas as amostras apresentaram bandas de 150, 90 e $65 \mathrm{pb}$ (figura 2). Esse perfil, como mencionado na literatura, é característico do subtipo B (Pienniazek et al., 1995). Podemos verificar, então, que nessa amostragem a prevalência do subtipo B foi de $100 \%$. 


\section{Discussão}

O presente trabalho é de fundamental importância na obtenção de dados que possam subsidiar o conhecimento da variabilidade genética do HIV-1, que ocorre no Distrito Federal.

Nós analisamos 22 amostras positivas para o HIV-1, coletadas no ano de 1998, no Instituto de Saúde do DF, para determinar a prevalência dos subtipos virais nesta região do Brasil. Todas as amostras analisadas apresentaram perfil de digestão do gene da protease compatível com o subtipo B do HIV-1. Esse é o primeiro estudo de caracterização de subtipos de HIV-1, realizado no DF e nossos dados demonstram a predominância do subtipo $\mathrm{B}$, reforçando a conclusão de que o subtipo B deve ser o mais freqüente no Brasil (Sabino et al., 1996; Diaz et al., 1997; Rossini et al., 2001).

Ainda assim, a distribuição dos subtipos do HIV-1 no Brasil parece ser complexa, pois suas prevalências podem diferir significativamente entre regiões bem próximas. Assim, é importante manter o monitoramento da variabilidade do HIV-1 no Brasil, durante a próxima fase da epidemia quando, provavelmente, haverá competição entre os diferentes subtipos virais. Deve-se levar em consideração que a distribuição de subtipos possui determinantes locais e que os dados de uma região não podem ser generalizados para todo o país e, nem mesmo, para toda uma região (Rossini et al., 2001).

Subtipos distintos e variantes de um mesmo subtipo podem diferir em suas propriedades biológicas. Dessa forma, diferenças com relação à capacidade de transmissão e ao potencial de causar doença podem alterar, drasticamente, as previsões sobre o futuro da epidemia causada pelo HIV-1. O estudo da variabilidade biológica natural do vírus pode fornecer informações importantes para intervenções clínicas racionais com o objetivo de alterar ou mesmo interromper a progressão da doença (Kanki et al., 1999).

Trabalhos subseqüentes deverão ser conduzidos para determinar o perfil de resistência aos anti-retrovirais, nessas amostras. 


\section{ANEXO 1}

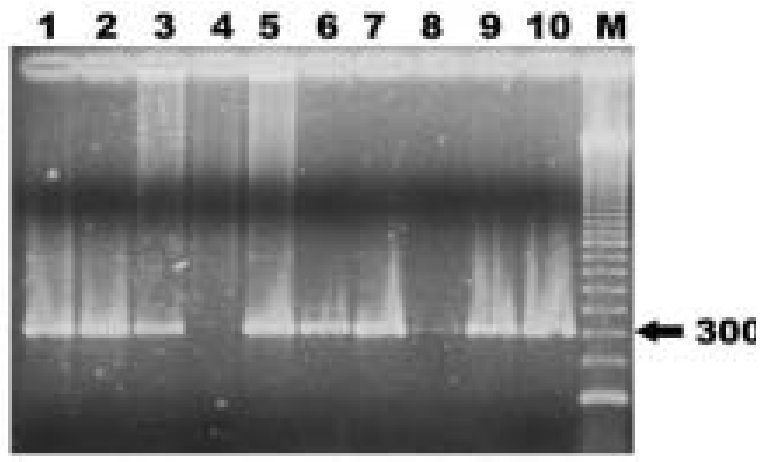

Figura 1. Fotografia do gel de agarose $1 \%$. Os poços 1, 2, 3, 5, 6,7, 8, 9 e 10 mostram a amplificação do gene da protease com 297 pb. M: marcador 100pb. No poço 4 está o controle negativo.

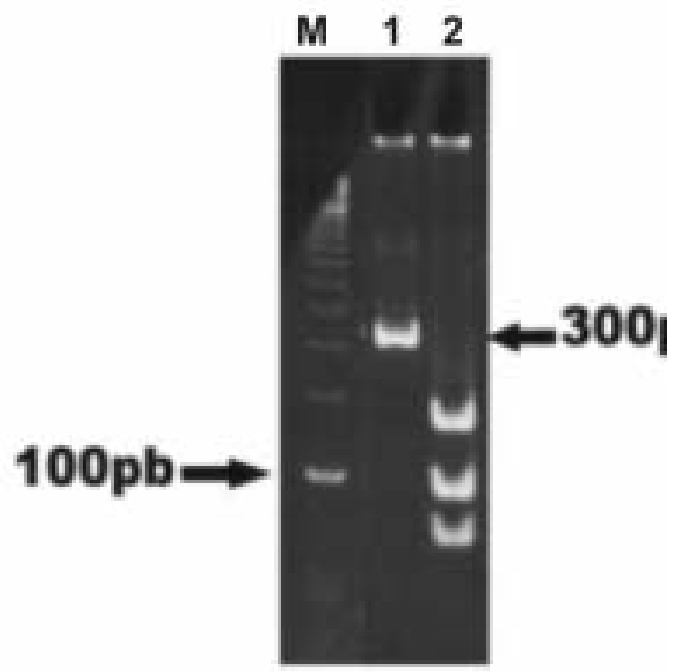

Figura 2. Fotografia do gel de poliacrilamida $15 \%$. M: marcador $100 \mathrm{pb}$. Poço 1: amostra não digerida; poço 2: amostra digerida com Alu I, apresentando perfil característico do subtipo B (bandas com 150, 90 e 65 pb). 


\section{Referências bibliográficas}

ALVAREZ, L.P.; CUEVAS, M.T.; VILLAHERMOSA, M.L.; PEDREIRA, J.D.; MANJÓN, N.; HERRERO, I.; CALVO, S.L.; DELGADO, E.; DE PARGA, E. V.; MEDRANO, L.; THOMSON, M.M.; TABOADA, J.A.; NÁJERA, R.; SPANISH GROUPFOR ANTIRETROVIRAL RESISTANCE STUDIES IN GALICIA. Prevalence of Drug Resistance Mutations in B, Non-B Subtypes, and Recombinant Forms of Human Immunodeficiency Virus Type 1 in Infected Individuals in Spain (Galicia). J. Hum. Virol., 4(1): 35-38, 2001.

BRASIL, MINISTÉRIO DASAÚDE. COORDENAÇÃONACIONALDE DSTE AIDS. Disponível na internet: www.aids.gov.br. Acesso em 10 de junho de 2002.

CARR, J.K.; FOLEY, B.T.; LEITNER, T.; SALMINEN, M.; KORBER, B.; MCCUTCHAN, F. Reference Sequences Representing the Principal Genetic Diversity of HIV-1 in the pandemic. http://idiotypo.lanl.gov/align_current/subtype-ref/subtype.html, 2000.

COSTA, L.J.; MUNERATO, P.; DIAZ, R.S.; TANURI, A. Generation of Intersubtype Human Immunodeficiency Virus Type 1 Recombinants in env Gene In Vitro: Influences in the Biological Behavior and in the Establishment of Productive Infections. Virology, 268: 440-451, 2000.

DIAZ, R.S.; LINQI, Z.; BUSCH, M.P.; MOSLEY, J.W.; MAYER, A. Divergence of HIV-1 quasispecies in an epidemiologic cluster. AIDS, 11: 415-422, 1997.

KANKI, P.J.; HAMEL, D.J.; SANKALE, J.L.; HSIEH, C.; THIOR, I.; BARIN, F.; WOODCOCK, S.A.; GUEYE-NDIAYE, A.; ZHANG, E.; MONTANO, M.; SIBY, T.; MARLINK, R.; NDOYE, I.; ESSEX, M.E.; MBOUP, S. Human immunodeficiency virus type 1 subtypes differ in disease proogression. J. Infect. Dis., 179: 68-73, 1999.

MINISTÉRIO DA SAÚDE - COORDENAÇÃO NACIONAL DE DST E AIDS. Estudo Piloto de Resistência do HIV aos Anti-retrovirais nos pacientes tratados pelo Consenso do Ministério da Saúde - Manual de Treinamento, 2000.

PIENNIAZEK, D.; JANINI, L.M.; RAMOS, A.; TANURI, A.; SCHECHTER, M.; ERALTA, J.M.; VICENTE, A.C.P.; PIENIAZEK, N.J.; SCHOCHETMAN, G.; RAYFIELD, M. A. HIV-1 patients May Harbor Viruses of Different Phylogenetic Subtypes: Implications for the Evolution of the HIV/AIDS. Pandemic. Emerg. Infec. Dis., 1: 8688, 1995.

ROBERTSON, D.L.; ANDERSON, J.P.; BRADAC, J.A.; CARR, J.K.; FOLEY, B.; FUNKHOUSER, R.K.; GAO, F.; HAHN, B.H.; KALISH, M.L.; KUIKEN, C.; LEARN, G.H.; LEITNER, T.; MCCUTCHAN, F.; OSMANOV, S.; PEETERS, M.; PIENNIAZEK, D.; SALMINEM, M.; SHARP, P.M.; WOLISKY, S.; KORBER, B. HIV-1 Nomenclature Proposal. A Reference Guide to HIV-1 Classification. http:// idiotype.lanl.gov/HTML/reviews/nomenclature/Nomen.html, 2000.

ROSSINI, M.A.A.; DIAZ, R.S.; CASEIRO, M.; TURCATO, G.; ACCETTURI, C.A.;

SABINO, E.C. HIV-1 subtypes among intravenous drug users from two neighboring cities in São Paulo State, Brazil. Braz. J. Med. Biol. Res., 34: 45 - 47, 2001. 
SABINO, E.S.; DIAZ, R.S.; BRIGIDO, L.F.; LEARN, G.H.; MULLINS, J.I.; REINGOLD, A.L.; DUARTE, A.J.S.; MAYER, A.; BUSCH, M.P. Distribution of HIV-1 Subtypes seen in an AIDS clinic in São Paulo City, Brazil. AIDS, 10: 1579-1584, 1996.

SAMBROOK, J.; FRITSCH, E.F.; MANIATIS, T. Molecular Cloning - A Laboratory manual. Code Spring Harbor Laboratory Press, 1989.

VAN REGENMORTEL, M.H.V.; FAUQUET, C.M.; BISHOP, D.H.L.; CARSTENS, E.B.; ESTES, M.K.; LEMON, S.M.; MANILOFF, J.; MAYO, M.A.; MCGEOCH, D.J.; PRINGLE, C.R.; WICKNER, R.B. (ed.). Virus Taxonomy Seventh Report of the International Committee on Taxonomy of Viruses. Academic Press, 2000, 1162p. 